\title{
Calcitonin-Like Polypeptides without Apparent Biological Activity in a Patient with Recurrent Medullary Thyroid Carcinoma
}

\author{
Katsuaki NaKaJima, Izumi JinkawA*, Takashi Hirota*, Toshihiko IKedA*, \\ Mamiko Tugawa, Yuzo Minami and Masato Hanada**
}

\begin{abstract}
A 51-year-old male with a recurrent medullary thyroid carcinoma (MTC) showed high serum levels of calcitonin (CT) and carcinoembryonic antigen (CEA) but with concomitant normocalcemia. The CT activities of the patient's serum in vivo (hypocalcemic activity in rats) and in vitro (cyclic AMP-increasing activity in cultured human mammary tumor, T47D) were much lower than those expected from the patient's CT level. High performance liquid chromatography (HPLC) with radioimmunoassay (RIA) detection gave a broad spectrum of molecular weights of CT-like polypeptides in the $3 \mathrm{kDa}$ to $200 \mathrm{kDa}$ range with separation from CEA, suggesting that the mechanism for CT production in MTC is an obscure one.
\end{abstract}

(Internal Medicine 34: 896-900, 1995)

Key words: calcitonins of various molecular weights

\section{Introduction}

Calcitonin (CT) is a hypocalcemic hormone secreted from $\mathrm{C}$-cells of the thyroid gland. It consists of 32 amino acids and has a molecular weight of about 3,400. CT is also known as a specific tumor marker for medullary thyroid carcinoma (MTC) (1). MTC usually produces a large amount of CT but there has been relatively few cases reporting the clinically overt hypocalcemic symptoms in MTC patients (2). We came to recognize that MTC was recurrent in one particular male patient who showed a normal calcium concentration despite having an extremely high serum CT level. Immunoreactive but apparently biologically inactive CTs with various molecular weights were observed in this patient, indicating that a complex mechanism for the production of $\mathrm{CT}$ is inherent in this particular case. Investigation of these CTs should support at least in part many other reported cases of extremely high CT levels determined by RIA assay in normocalcemic MTC patients.

\section{Case Report}

A markedly high serum carcinoembryonic antigen (CEA) concentration was observed in an asymptomatic 51-year-old male during a routine blood examination. He also showed an elevated serum CT level. He had undergone a left-lobe thyroid- ectomy with simultaneous cervical lymph node dissection for MTC of sporadic type 12 years previously. Scintigraphy with a pentavalent 99mTc-DMSA (dimercaptosuccinic acid) delineated two hot spots suspected of MTC recurrence in the upper anterior mediastinum. No other malignancy was found during elaborate investigations of his internal viscera. He was hospitalized for removal of the mediastinal masses. On admission, the serum levels of CT and CEA were, respectively, $14,400 \mathrm{pg} / \mathrm{ml}$ (normal value: $<100$ ) and $184.4 \mathrm{ng} / \mathrm{ml}$ (normal value: $<5.0$ ). The serum calcium concentration of $4.9 \mathrm{mEq} / l$ was within the normal limit, and the parathyroid hormone was not observed to be at an abnormally high level (less than $0.6 \mathrm{ng} / \mathrm{ml}$ ). No endocrine function was disturbed except for a slight hypothyroidism due to the partial thyroidectomy. On September 30, 1993, the masses were resected with the upper half of the thymus and adjacent connective tissues. The tumor was confirmed pathologically as mediastinal lymph node recurrence of MTC. Almost all of the tumor cells contained both CT and CEA, which were confirmed by immunohistochemical staining (Fig. 1). The patient recovered uneventfully, but, unexpectedly, decreases in the serum levels of CT and CEA were not detected during the three months after surgery, showing values of 12,400 $\mathrm{pg} / \mathrm{ml}$ and $212 \mathrm{ng} / \mathrm{ml}$, for each, respectively at this time. A postoperative scintiscan disclosed new lesions localized diffusely in the middle anterior mediastinum which had not been delin-

From the Department of Internal Medicine, Osaka Central Hospital, Osaka, *the Analytical and Metabolic Research Laboratories, Sankyo Co., Ltd., Tokyo and **the Department of Pathology, Toyonaka Municipal Hospital, Toyonaka Received for publication August 11, 1994; Accepted for publication June 5, 1995 Reprint requests should be addressed to Dr. Katsuaki Nakajima, 2-17-B208, Senriyama Higashi, Suita 565 

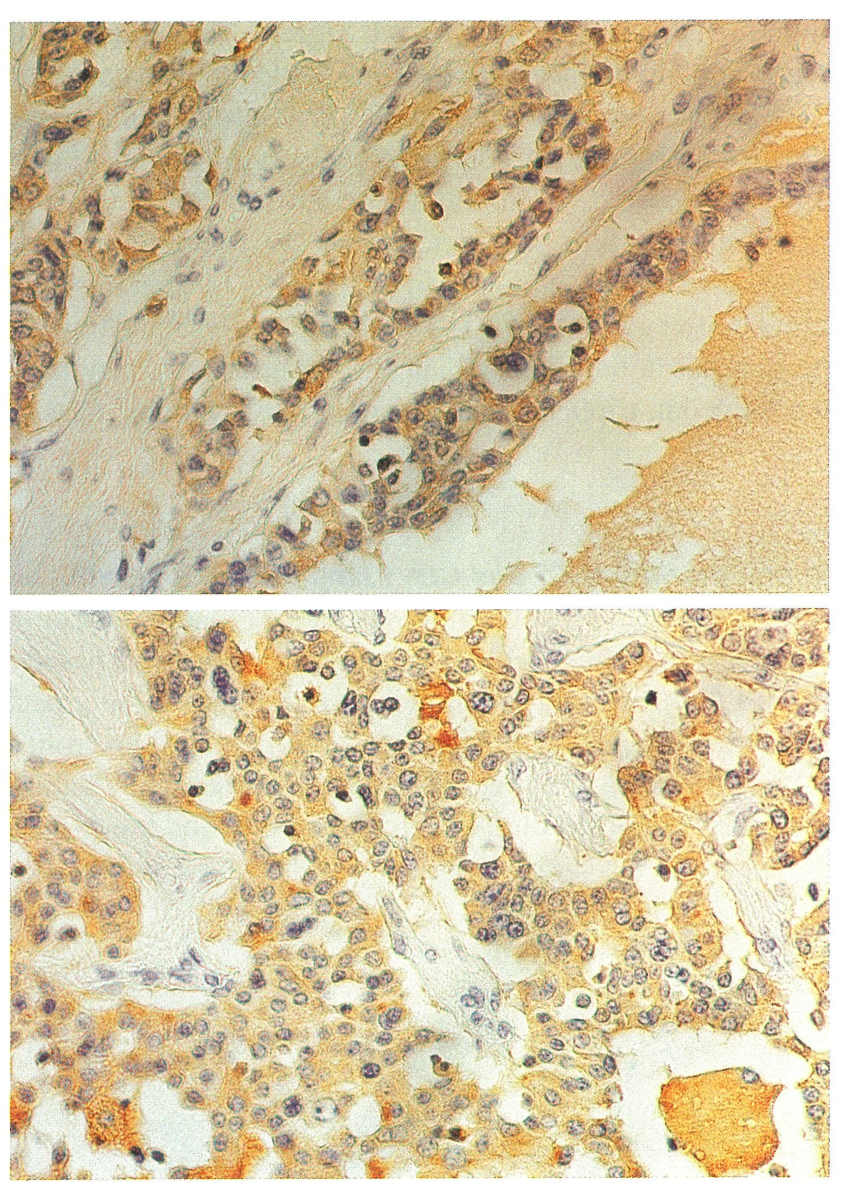

Figure 1. Photomicrographs of immunohistochemical staining of the resected specimen with anti-calcitonin (CT) and anticarcinoembryonic antigen (CEA) antibodies. Upper: Staining with anti-CT antibody, $\times 200$. Lower: Staining with anti-CEA antibody, $\times 200$. CT was noted both in the cytoplasm and in the stroma. CEA was stained not only in the cytoplasmic membrane but diffusely in the cytoplasm. AL-type amyloid was found to be deposited in the stroma.

eated on the previous scintigram. The serum CT level increased to $39,000 \mathrm{pg} / \mathrm{ml}$ by November 22,1994 . It should be noted at this juncture that a careful follow-up observation of the patient would obviate whether any future reoperation is necessary. This case report is described in detail elsewhere (3).

\section{Materials and Methods}

\section{Materials}

Serum samples of the patient were obtained in December 1993 before and after infusion of calcium chloride, which was performed at a dose of $12 \mathrm{mg} / \mathrm{kg}$ over a period of 15 minutes (4). The samples were stored frozen at $-80^{\circ} \mathrm{C}$ until analysis (CT levels before and after calcium infusion were $22,890 \mathrm{pg} / \mathrm{ml}$ and $41,470 \mathrm{pg} / \mathrm{ml}$, respectively). Another serum sample was obtained in November 1994, without calcium infusion (CT level:
$39,000 \mathrm{pg} / \mathrm{ml})$. The CT concentrations of the samples were determined by a CT assay kit (Mitsubishi-Yuka, Tokyo, Japan). CEA concentration was determined by CEA RIA BEAD of Dainabot (Tokyo, Japan). C-Test Wako for measurement of serum calcium was purchased from Wako Pure Chemical Industries (Tokyo, Japan). Human calcitonin (h-CT) and CEA were obtained from the Peptide Institute Inc. (Osaka, Japan) and the Israel Institute for Biological Research (Tel Aviv, Israel), respectively. Cyclic AMP (cAMP) was determined by CYCLIC AMP KIT "YAMASA" (Yamasa Soy Sauce, Tokyo, Japan). The gel filtration column (TSK gel-3000) for high performance liquid chromatography (HPLC) was purchased from Tosoh (Tokyo, Japan).

\section{HPLC analysis of molecular weight profiles of CT and CEA}

The serum samples collected from the patient before and after the calcium infusion test (December 1993) were separated by HPLC equipped with a gel filtration column in order to investigate the molecular weight distributions of CT and CEA. The apparatus used and operating conditions for high performance liquid chromatography (HPLC) were as follows. Pump, Model PX-8010 (Tosoh); Detector, Model UV-8010 (Tosoh); Detection wave length, $280 \mathrm{~nm}$; Column temperature, Room temperature; Mobile phase, $50 \mathrm{mM}$ Potassium phosphate buffer (pH 6.5); Flow rate, $0.5 \mathrm{ml} / \mathrm{min}$; Injection volume, $0.1 \mathrm{ml}$.

The fractions were collected at 1 minute intervals, and the concentrations of CT and CEA in each fraction were measured by commercially available RIA kits.

\section{In vivo CT assay for hypocalcemic activity of the patient's serum in rats}

Male Sprague-Dawley (SD) rats (body weight: $57 \pm 2 \mathrm{~g}$ ), allowed free access to food and water until the experiments, were used. The patient's serum (CT level: 39,000 pg/ml, November 1994) was administered to three rats at a dose of 2.56 $\mathrm{ml} / \mathrm{kg}$ (100 ng-equivalent CT/ $\mathrm{kg}$ ), and about $1 \mathrm{ml}$ of blood was collected from each by cardiac puncture using a heparinized syringe 30 minutes after administration. h-CT in saline as a positive control was also administered to rats at a dose of 100 $\mathrm{ng} / \mathrm{kg}$. The concentrations of CT in the dosing solutions were determined by RIA to confirm the CT dose. An equivalent volume of physiological saline was administered to the control animals. Rat plasma samples were prepared by centrifugation immediately after blood sampling, and stored frozen at $-80^{\circ} \mathrm{C}$ until analysis. Plasma calcium levels in $\mathrm{mEq} / \mathrm{l}$ were measured by an assay kit in duplicate.

In the experiment to examine the occurrence of any substances suppressing CT activity in the patient, serum samples from either the patient (CT level: 22,890 pg/ml, December 1993 , before calcium infusion) or a healthy control volunteer were injected intravenously at a dose of $1 \mathrm{ml} / \mathrm{kg}$ to SD immature rats (body weight: $50 \pm 2 \mathrm{~g}$ ), alone or after admixture with 100 or $1,000 \mathrm{ng} / \mathrm{kg}$ of $\mathrm{h}-\mathrm{CT}$, and the plasma calcium levels of rats were measured in the same way as above.

Data were expressed as mean $\pm \mathrm{SE}$, and compared statistically by Student's t-test. A difference at a level of $p<0.05$ in the 
two-tailed test was regarded as statistically significant.

In vitro CT assay using human mammary tumor cells, T47D

T47D, the human mammary tumor cells which show an increase in cAMP in response to CT, were obtained from ATCC (5). The cells were placed in a plate with 24 wells $\left(2.0 \times 10^{5}\right.$ cells/ well), and cultured in RPMI 1640 medium (GIBCO, New York, U.S.A.) containing 10\% calf fetal serum (Morgate, Australia), insulin (200 IU/l, Sigma, St. Louis, MO, U.S.A.), penicillin (50,000 IU/l, Sigma) and streptomycin (50 mg/l, Sigma) at $37^{\circ} \mathrm{C}$ for 3 days in an atmosphere of $95 \% \mathrm{O}_{2}$ and $5 \% \mathrm{CO}_{2}$. After washing the cells twice with phosphate buffered saline (PBS) warmed at $37^{\circ} \mathrm{C}, 200 \mu \mathrm{l}$ of the warmed PBS was added to each well, and the plate was incubated at $37^{\circ} \mathrm{C}$ for 40 minutes. PBS $(100 \mu \mathrm{l}$ ) containing $20 \%$ patient serum (CT level: $39,000 \mathrm{pg} / \mathrm{ml}$, November 1994, final 4\%) or the control human serum supplemented with h-CT at varying concentrations as standards, was added to the well, and the plate was incubated for a further 30 minutes. For inhibition of the phosphodiesterase, PBS was added with $7.5 \mathrm{mM} 3$-isobutyl-1-methylxanthine at the same time (final concentration: $1.5 \mathrm{mM}$, Sigma). The volume of the incubation mixture was adjusted to $500 \mu \mathrm{l}$ with PBS containing $1.5 \%$ bovine serum albumin (final $0.3 \%$, Sigma). As the deviation from the nominal concentration was predicted to occur after successive dilution, the final concentration of CT in the incubation mixture was determined by radioimmunoassay (RIA). cAMP was extracted from the cells by shaking for 30 minutes after addition of $30 \mu \mathrm{l}$ of $1 \mathrm{~N} \mathrm{HCl}$. After centrifugation, the concentration of cAMP in the supernatant fraction was determined in triplicate by a commercially available RIA kit.

\section{Results}

\section{Elution profiles of CT and CEA in the patient's serum}

CT in the patient's serum was detected broadly in fractions ranging from 10 to 30 (collection rate: 1 fraction/min) based on the HPLC chromatogram, showing a multitude of minor peaks but no major peak, while CEA was found in fractions from 12 to 15 with a clear single peak (Fig. 2B, solid line). The serum CT level nearly doubled during the calcium infusion test (3) (Fig.

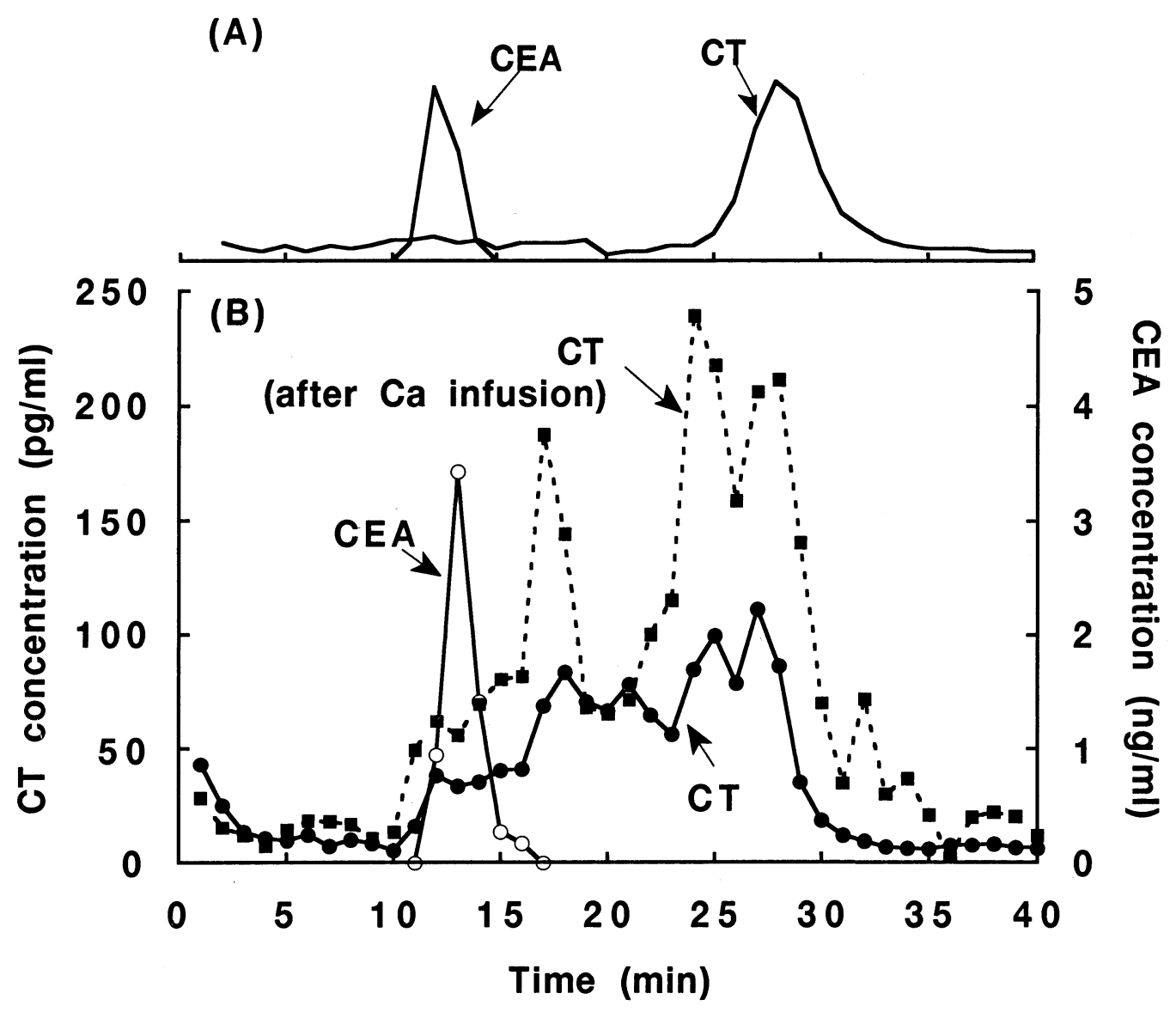

Figure 2. Elution profiles of calcitonin (CT) and carcinoembryonic antigen (CEA) in the patient's serum. (A) Elution profiles of authentic CT and CEA added to the control serum. Data are shown only to indicate the elution positions of authentic CT and CEA. (B) Solid lines, closed and open circles: Elution profiles of CT and CEA, respectively, in the patient's serum before Ca infusion. Dashed line, closed squares: Elution profile of $\mathrm{CT}$ in the patient's serum after $\mathrm{Ca}$ infusion. 
2B, dashed line). However, CEA remained unchanged (before infusion: $125 \mathrm{ng} / \mathrm{ml}$; after infusion: $114.6 \mathrm{ng} / \mathrm{ml}$ ). There was virtually no alteration in the elution patterns of CT before and after the calcium infusion, with one minor exception being in fractions from 19 to 21 (Fig. 2B). In chromatograms of the control serum supplemented with both authentic h-CT and CEA, CT was detected in the fractions from 26 to 31 and CEA from 12 to 15, each showing a clear single peak (Fig. 2A).

\section{CT activities of the patient's serum}

In vivo assay

Plasma calcium levels were determined in rats 30 minutes after administration of either saline, $\mathrm{h}-\mathrm{CT}$ in saline $(100 \mathrm{ng} / \mathrm{kg})$ or the patient's serum (100 ng-equivalent CT/kg). The mean calcium concentration of the saline-treated control group was $4.93 \pm 0.06 \mathrm{mEq} / \mathrm{l}(100 \%)$, and that of the h-CT group was $4.23 \pm 0.04 \mathrm{mEq} / \mathrm{l}(85.8 \pm 0.7 \%, \mathrm{p}<0.01)$ (Fig. 3). The group treated with the patient's serum showed a calcium level of $4.63 \pm 0.03 \mathrm{mEq} / \mathrm{l}(91.2 \pm 0.4 \%, \mathrm{p}<0.01)$, and therefore, the hypocalcemic action of the patient's serum was found to be much lower than that expected from his CT level.

Administration of the patient's serum admixed with h-CT decreased the plasma calcium levels of rats dose dependently (Control: $5.18 \pm 0.09 \mathrm{mEq} / l, 100 \mathrm{ng} / \mathrm{kg}: 4.75 \pm 0.24 \mathrm{mEq} / l, 1,000$ $\mathrm{ng} / \mathrm{kg}: 4.21 \pm 0.12 \mathrm{mEq} / \mathrm{l}, \mathrm{p}<0.01$ ), approximately to the same levels as those achieved by the control serum admixed with equal amounts of h-CT (Control: $5.33 \pm 0.12 \mathrm{mEq} / l, 100 \mathrm{ng} / \mathrm{kg}$ : $4.77 \pm 0.25 \mathrm{mEq} / \mathrm{l}, 1,000 \mathrm{ng} / \mathrm{kg}: 4.51 \pm 0.13 \mathrm{mEq} / l, \mathrm{p}<0.01)$. Therefore, the substances suppressing the hypocalcemic action of CT were not indicated to be present in the patient's serum. In vitro assay

The dose-response curve for the increase in cellular cAMP in T47D as a function of $\mathrm{h}-\mathrm{CT}$ concentration in the medium is shown in Fig. 4. According to this curve, the final concentration of CT in the medium after addition of the patient's serum was calculated to be $188 \pm 0.02 \mathrm{pg} / \mathrm{ml}$ (Fig. 4 , open circle), which was only $23 \%$ of that determined for the medium by RIA $(806 \pm 0.02$ $\mathrm{pg} / \mathrm{ml}$ ). Therefore, the biological activity of CT in the patient's serum was again demonstrated to be much lower than that expected from his CT level.

\section{Discussion}

Most MTC patients are known to clinically manifest high serum levels of CT without hypocalcemia. The patient in this study also showed normocalcemia and normal-appearing parathyroid hormone levels irrespective of a high CT concentration. Gel filtration HPLC demonstrated that the patient's serum contains RIA-detectable CTs of various molecular weights. Calcium infusion resulted in about a two-fold increase in these CTs, which were considered to be secreted from MTC in response to the calcium challenge. In both in vivo and in vitro experiments, the patient's serum showed low but observable CT activities, which were, however, quite inconsistent with the observed high CT level by RIA. No substances suppressing the hypocalcemic action of CT appeared to be in the serum. CTs

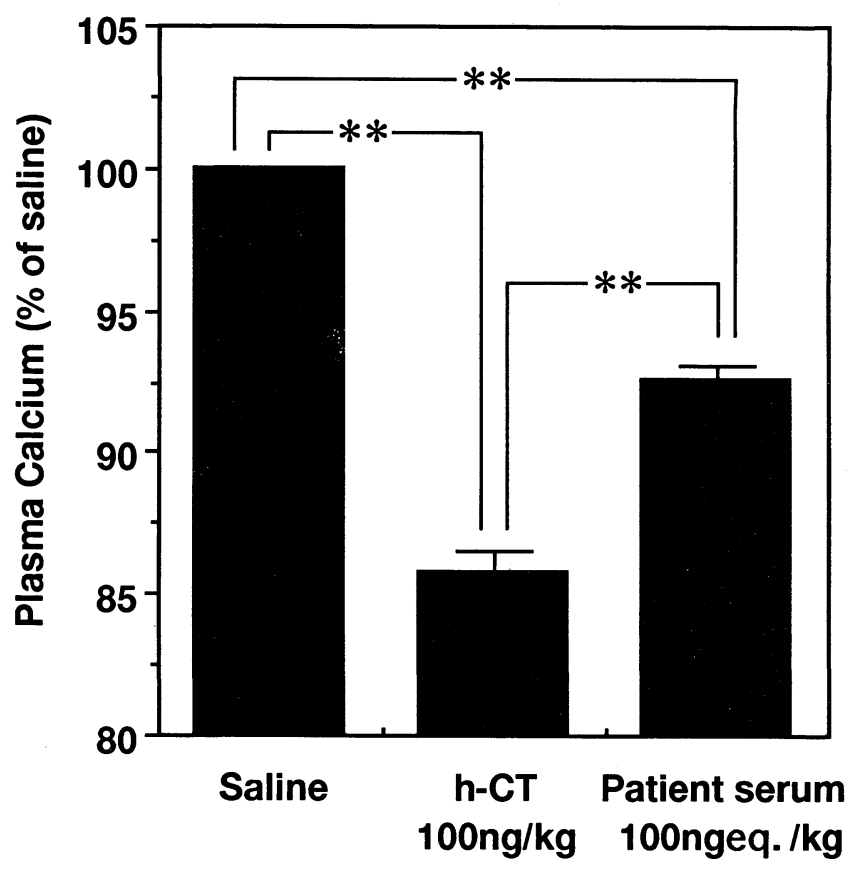

Figure 3. Comparison of hypocalcemic activity in rats between the patient's serum and authentic human calcitonin (h-CT) in control serum. Plasma calcium levels 30 minutes after administration of the patient's serum and h-CT are shown in terms of percentage to saline control. ${ }^{* *}$ : $\mathbf{p}<0.01$.

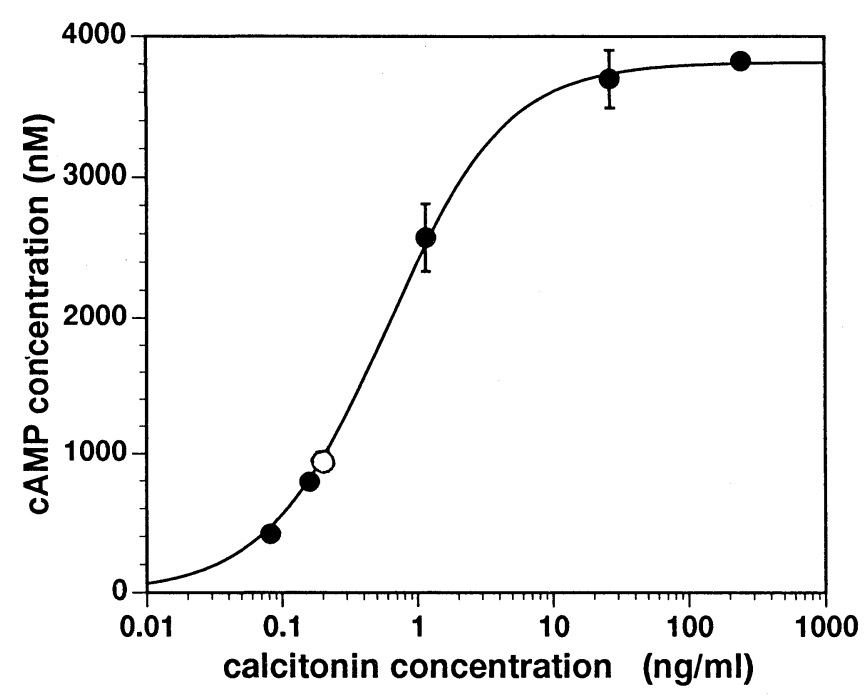

Figure 4. Dose-response curve of the increase in cAMP in T47D and human calcitonin ( $h-C T)$ concentration. Closed circles: h-CT in control serum (final $4 \%$ ) as a standard. Open circle: patient's serum (final 4\%).

with high molecular weight are, therefore, very unlikely to have biological activity. The normal calcium level in the patient may be explained in part by the biologically inactive CTs. However, assuming that the CT activity in the patient's serum is ascribed 
to the intact CT, the level of the intact CT in the patient's serum based on the in vitro assay using T47D was calculated to be $8,970 \mathrm{pg} / \mathrm{ml}$ (as $23 \%$ of the serum level by RIA), which was still higher than the normal level. Another plausible argument is that the normal calcium level in the patient may be a consequence of down-regulation of CT receptors caused by a continuously high level of serum CT.

Serum CEA values are also known to be elevated in most MTC cases. CT and CEA molecules are generally considered to exist without association in the serum, since each substance behaves independently in response to stimulation tests (6). Our patient showed no increase in CEA level in the calcium infusion test irrespective of an approximate doubling of the CT level. The HPLC elution profile of the patient's serum revealed an obvious dissociation of CT from CEA, providing further evidence for the lack of coupling of these two substances. Furthermore, the observed CT level in the patient's serum remained unchanged after elimination of CEA by centrifuging the serum after addition of anti-CEA antibody, which also indicated that there was a lack of binding of these two molecules (data not shown). Therefore, a masking of the CT activity by CEA, which may lead to normocalcemia, is not thus very likely. The mechanism of simultaneous excess production of these two molecules in MTC still remains to be resolved.

The human CT gene is believed to consist of at least three distinct members (7). Only one of these members is capable of producing the CT-mRNA which subsequently gives the CT precursor polypeptide after alternative RNA splicing, during which the RNA sequence of calcitonin gene-related protein is excluded $(8,9)$. The CT precursor polypeptide is considered to be subsequently converted to the mature CT molecule through protease processing (9). The polypeptides with various molecular weights having the epitope sequence of $\mathrm{CT}$ in the present patient suggest an impaired post-translational proteolytic processing of the CT precursor protein, or, more conjecturally, the generation of multiple CT-associated mRNAs in MTC.

\section{References}

1) DeLellis RA, Rule AH, Spiler I, et al. Calcitonin and carcinoembryonic antigen as tumor markers in medullary thyroid carcinoma. Am J Clin Pathol 70: 587, 1978.

2) Melvin KEW, Tashjian AH, Miller HH. Studies in familial (medullary) thyroid carcinoma. Rec Prog Horm Res 28: 399, 1972.

3) Nakajima K, Itakura T, Mori T, et al. Upper mediastinal recurrence of medullary thyroid carcinoma 12 years after initial thyroidectomy. Jpn J Cancer Clin 40: 855, 1994 (in Japanese).

4) Kodama T, Fujino M, Endo T, et al. Family study of serum carcinoembryonic antigen in inherited medullary carcinoma of the thyroid. Cancer 44: 661, 1979.

5) Lamp SJ, Findlay DM, Moseley JM, et al. Calcitonin induction of a persistent activated state of adenylate cyclase in human breast cancer cells (T47D). J Biol Chem 256: 12269, 1981.

6) Calmettes C, Moudktar MS, Milhaud G. Correlation between calcitonin and carcinoembryonic antigen levels in medullary carcinoma of the thyroid. Biomedicine 27: 52, 1977.

7) Lips CJM, Geerdink RA, Nieuwenhuis MG, et al. Evolutionary pathways of the calcitonin (CALC) genes. Henry Ford Hosp Med J 37: 201, 1989.

8) Cote GJ, Stolow DT, Peleg S, et al. Identification of exon sequences and an exon binding protein involved in alternative RNA splicing of calcitonin/CGRP. Nucl Acids Res 20: 2361, 1992.

9) Amara SG, Jonas V, Rosenfeld MG, et al. Alternative RNA processing in calcitonin gene expression generates mRNAs encoding different polypeptide products. Nature 298: 240, 1982. 